\title{
262. A Preliminary Note on a Case of Trisomic \\ Down's Syndrome with a Short Arm Deletion of a G Group (21-22) Chromosome
}

\author{
By Naoki Ito and Sajiro MaKino \\ Department of Psychiatry and Neurology, School of Medicine \\ and Department of Zoology, Faculty of Science, \\ Hokkaido University, Sapporo \\ (Comm. by Yoshimaro TANaKa, M.J.A., Dec. 12, 1966)
}

Since the initial description of the G group trisomy in Down's syndrome (Lejeune, Turpin, and Gautier 1959) much work has been done on the cytogenetics of this syndrome. We here present our findings in an interesting case of trisomic Down's syndrome with a deleted short arm of one of the G group chromosomes.

Evidence of a short arm deletion in the $G$ group chromosomes has recently been presented by several authors (Gunz et al. 1962, Shaw 1962, Migeon 1965, Šubrt and Brychnáč 1966, Neu et al. 1966). It is a general feature that this aberration is not associated with any particular disease. Familial surveys have made it clear that many phenotypically normal persons carry this chromosome abnormality. Shaw (1962) is the first to report the chromosome aberration of a similar type in a patient with Down's syndrome. While doing a chromosomal survey in mentally retarded patients, we have observed a patient with trisomic Down's syndrome with a short arm deletion of one of the G group (21-22) chromosomes.

Case report. The propositus was a 7 year old mentally retarded girl born to a 43 year old mother and 49 year old father. There was no history of abortion or stillbirth. Among the 10 older siblings, the third, fifth and seventh children died in early infancy because of malnutrition or pneumonia. Her parents and seven living siblings were found to be phenotypically normal without evidence of mental deficiency. The birth weight of the propositus was $3000 \mathrm{~g}$. The child at birth was noted to have a feeble cry, poor suck, and

Table I. Dermatoglyphic patterns of the patient

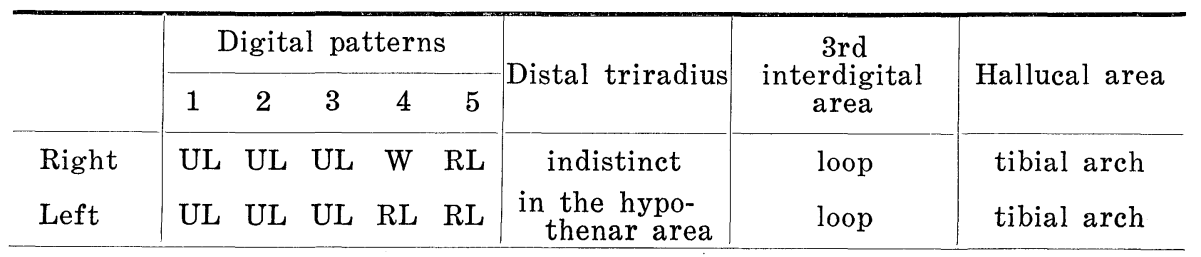

UL: ulnar loop. RL: radial loop. W: whorl. 
muscle hypotonia. The retardation of development was striking: she walked when she was four years old. She was susceptible to various infections, and had many episodes of high fever with seizures. At six years of age she first called her attention with her parents' names and several words. She liked to mimic everybody around her.

On examination she showed a marked degree of developmental retardation, being $106 \mathrm{~cm}$ in height and $19 \mathrm{~kg}$ in weight. The degree of her mental retardation was on the borderline between idiocy and imbecility. Her head was characterized by both microcephaly and brachycephaly. The palpebral fissures were oblique with a marked epicanthus. Strabismus convergens and mild conjunctivitis were also recognized. The nasal bridge was flat. A high-arched palate was noted. The tongue was large but without scrotal appearance. The teeth were small and irregularly aligned. Her voice was characteristically low. The fingers were short, the fifth finger particularly being bowed slightly inwards. There were marked four-finger-lines on both palms. The dermatoglyphic patterns were analysed according to Penrose and Smith (1966) and were shown to be characteristic of Down's syndrome (Table I).

Cytological findings. The slides for chromosome observation were prepared from short term cultures of peripheral leukocytes

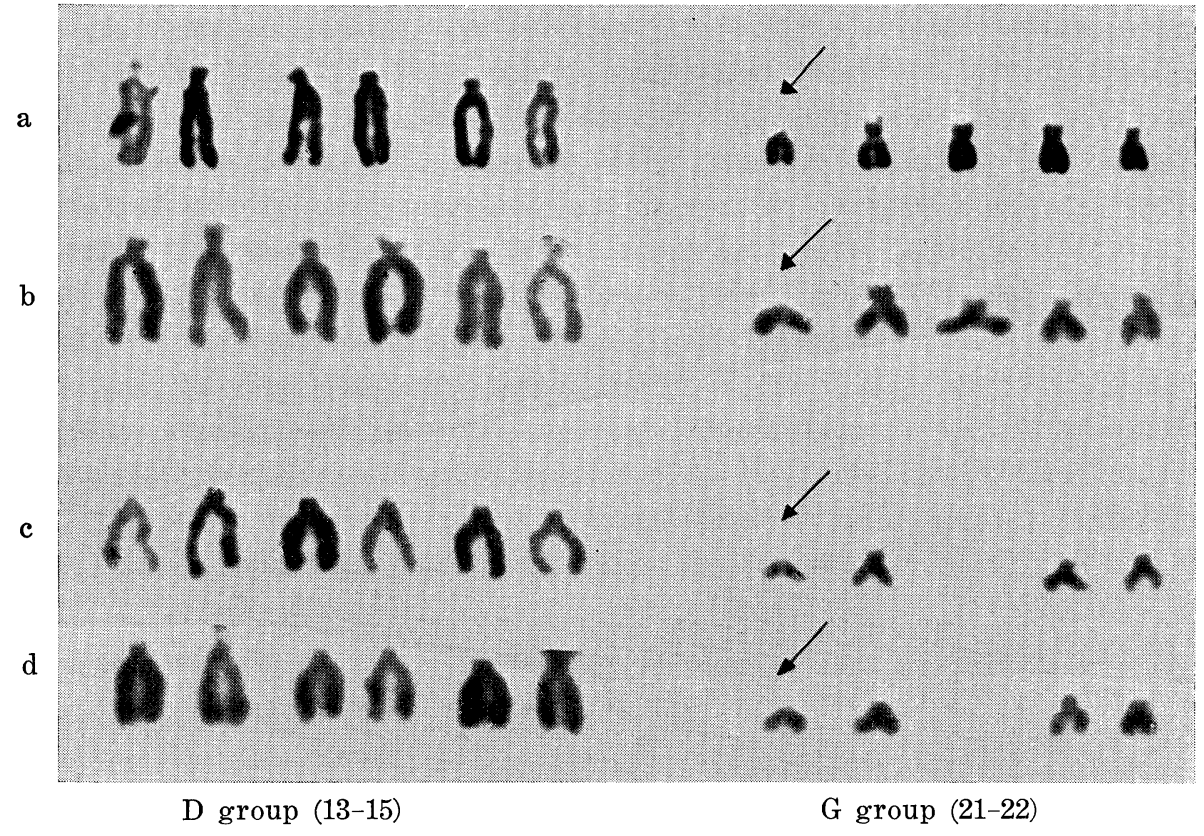

Fig. 1. a-b: Partial karyotypes from the propositus. c-d: Those from the mother. Arrow indicates a G group chromosome with a deleted short arm in each. 
according to a modification of Moorehead's method (1960). Chromosome counts were made on 30 well-spread metaphase cells from the patient and her parents. Karyotype analysis was carried out with special attention to the chromosomes of $\mathrm{G}$ and $\mathrm{D}$ groups. The karyotype of the patient was characterized by a 47/XX complement showing trisomy for one of the 21-22 chromosomes. Her mother was found to possess a normal female complement represented by $46 / \mathrm{XX}$. Close examination revealed that cells derived from both the patient and her mother showed a short arm deletion in one of the $G$ group (21-22) chromosomes. The deleted chromosome seemed not to be associated with satellites of other acrocentric chromosomes. Shaw (1962) described an elongation of the short arm of one of the D group chromosomes in a significant percentage of cells in a child with Down's syndrome and in her normal sib. No such aberration was noted in samples from the present kindred. Partial karyotypes of the patient and her mother are shown in Fig. 1, a-d. Phenotypically, her normal father had a normal male complement represented by $46 / \mathrm{XY}$ without evidence of the short arm deletion.

Remarks. The patient here considered was recognized as a case of typical Down's syndrome based on the clinical features and dermatoglyphic patterns. The cytological findings have made it clear that she is trisomic for a small element in the G group of presumably no. 21, and that one of the trisomic elements was characterized by a deletion of the short arm. Since her mother showed a short arm deletion of a similar nature in one of the G group chromosomes, it is very likely that the abnormal chromosome was transmitted from the mother to the patient.

Shaw (1962) observed in one of familial chromosome studies that one chromosome of the 21-22 group was unusually short in the healthy mother, one of her three Down's syndrome children and two normal sons. According to Shaw (1962), the short chromosome appeared to be telocentric consisting only of the long arm, and ending abruptly at the centromere. Based on the above facts, Shaw (1962) discussed the possibility that the short arm deleted chromosome was merely a marker element, and that its presence in the mother was not associated with the occurrence of the three children with Down's syndrome. Neu et al. (1966) reviewed the literature and concluded that the short arm deleted chromosome would be a familial autosomal variant because it was not associated with any particular disease.

On the other hand, Dent et al. (1963) described a case of atypical Down's syndrome who had 47 chromosomes with a deletion 
of half the long arm of the extra small element. The karyotypephenotype relationship observed in the present case, as well as in cases presented by Shaw (1962) and Dent et al. (1963), seems to suggest that a trisomic condition for the long arm of one of the $G$ group chromosomes is possibly associated with the occurrence of Down's syndrome. However, the identification of the aberrant chromosome as to no. 21 or no. 22 remains difficult at present. This question will be answered to some extent by means of autoradiographic techniques now in progress.

Detailed reports with some familial data now in preparation will be published elsewhere in the near future.

Summary. A 7 year old mentally retarded girl showing the typical signs of Down's syndrome, and her clinically normal parents were studied cytogenetically. It was found that the patient showed trisomy for one of the $G$ group chromosomes, and that one of the trisomic elements is characterized by a deletion of the short arm. Her phenotypically normal mother was found to possess a short arm deleted chromosome of a similar type in G group. Her normal father possessed a normal male complement.

Acknowledgements. The authors are grateful to Drs. Kyoji Nishibori and Masaya Inatsu for making available the clinical records of the patient and for assistance in collecting the material. Thanks are due to Dr. Motomichi Sasaki and Dr. A. D. Bloom for critical advice and valuable suggestions during our evaluation of this patient and her parents.

\section{References}

T. Dent, J. H. Edwards, and J. D. A. Delhanty (1963): Lancet, ii, 484-487.

F. W. Gunz, P. H. Fitzgerald, and A. Adams (1962): Brit. Med. J., 2, 1097-1099.

J. Lejeune, R. Turpin, and M. Gautier (1959): Ann. de Genetique, 1, 41-49.

B. R. Migeon (1965): Bull Johns Hopkins Hosp., 116, 396-402.

P. S. Moorehead, P. C. Nowell, W. J. Mellman, D. M. Battips, and D. A. Hungerford, (1960): Exptl. Cell Res, 20, 613-616.

R. L. Neu, J. C. Leao, and L. I. Gardner (1966): Lancet, ii, 390-391.

L. S. Penrose and G. F.Smith (1966): Dermatoglyphs, 57-75. In Down's Anomaly. $\mathrm{J}$ and $\mathrm{A}$. Churchill LTD. London.

M. W. Shaw, (1962): Cytogenetics, 1, 141-179.

I., Šbrt and V. Brychnac (1966): Lancet, i, 549. 